\title{
Posebne populacije bolesnika: Udružena ishemijska bolest srca i hronična bubrežna insuficijencija
}

\author{
Milan Nedeljković, Zlatko Mehmedbegović \\ Klinika za kardiologiju, Klinički centar Srbije; Medicinski fakultet, Univerzitet u Beogradu
}

$\mathrm{U}$ druženost između hronične bubrežne insuficijencije (HBI) i kardiovaskularnog mortaliteta je poznata i dokazana, i kao takva postoji dvosmerno. Naime, kardiovaskularni uzroci smrtnosti su češći kod pacijenata sa HBI u odnosu na opštu populaciju, kao što je i prognoza pacijenata sa dijagnostifikovanim oboljenjem kardiovaskularnog sistema i HBI znatno lošija u odnosu na bolesnike bez ovog pridruženog morbiditeta. Otuda miokardna revaskularizacija predstavlja jedan od bitnih aspekata lečenja pacijenata sa oštećenom renalnom funkcijom. Nažalost, i sama revaskularizaciona procedura, bilo da je to perkutanim pristupom sa upotrebom potencijalno nefrotoksičnog kontrastnog sredstva, ili da je to hirurškim pristupom i povezanim periproceduralnim hemodinamskim perturbacijama, može doprineti pogoršanju postojeće ili uzrokovati novonastalo ireverzibilno oštećenje bubrega. Stoga je neophodno, pre svega, identifikovati pacijente koji zahtevaju revaskularizaciju, a koji imaju bilo kakvo oštećenje bubrežne funkcije.

\section{Definicija HBI}

Za definisanje HBI neophodno je odrediti glomerularnu filtraciju (GFR), jer sama serumska vrednost kreatinina može se koristiti samo za grubu procenu bubrežnog stanja s obzirom na to da je sama vrednost zavisna od niza faktora kao sto su telesna masa, godine, pol, udeo mišićne mase, unos hranljivih materija, itd. Najčešće korišćena formula za izračunavanje GFR je Cockroft-Gault metod (http://www.clinicalculator.com/english/nephrology/coc$\mathrm{kroft} / \mathrm{cc} . \mathrm{htm})$, a normalne vrednosti su za mladog muškarca su približno $100-130 \mathrm{~mL} / \mathrm{min} / 1.73 \mathrm{~m}^{2}$, a za mladu ženu $90-120 \mathrm{~mL} / \mathrm{min} / 1.73 \mathrm{~m}^{2}$. Sama HBI se klasifikuje u 5 grupa u zavisnosti od težine bolesti i redukcije GFR, a kao značajno sniženje, sa prognostičke tačke gledišta, uzima se umereno sniženje sa GFR manjom od $60 \mathrm{~mL} / \mathrm{min} / 1.73 \mathrm{~m}^{2}$. Pored praćenja serumskog kreatinina, može se koristiti i novi senzitivniji marker bubrežne funkcije Cistatin C, za kojeg je utvrđeno da ima raniji porast u slučaju oštećenja kao i da je nešto specifičiniji kod pacijenata sa više od 75 godina starosti.

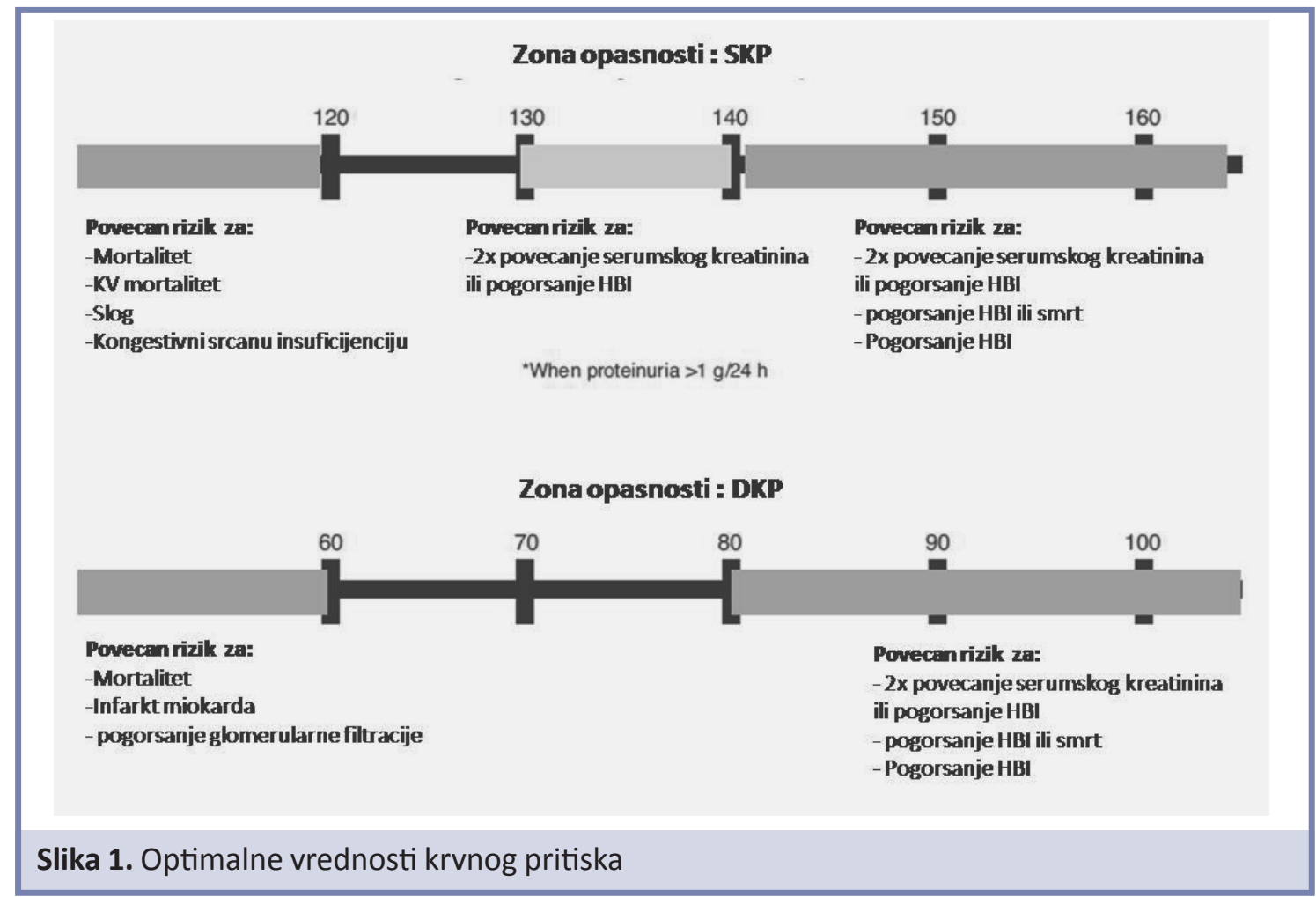

Kontakt osoba: Milan Nedeljković, Klinika za kardiologiju, Klinički centar Srbije, Koste Todorovića 8, 11000 Beograd 


\section{Medikamentna terapija ishemijske bolesti srca sistema kod pacijenata sa HBI}

Pravilna regulacija krvnog pritiska (KP) redukuje smrtnost kako od samog ishemijskog kardiovaskularnog oboljenja tako i usled napredovanja bubrežne bolesti. Postoji veliki broj kliničkih vodiča koji su definisali optimalni terapijski opseg vrednosti KP koji treba postići prilikom propisivanja antihipertenzivnih lekova, ali između njih ne postoji jasna saglasnost. Tri randomizovane studije (MDRD, REIN-2, AASK) ispitivale su efekat intenzivne regulacije KP kod bolesnika sa uobičajnom regulacijom KP kod pacijenata sa HBI, sa sećernom bolešću ili bez nje. .-3 $^{1-3}$

$\mathrm{Na}$ osnovu rezultata ovih studija došlo se do optimalnog opsega vrednosti za sistolni krvni pritisak kao i za donje granice za dijastolni krvni pritisak iznad i ispod kojih dolazi do povećanja rizika za nastanak neželjenih kardiovaskularnih događaja kao i do napretka HBI. Kod pacijenata sa $\mathrm{HBI}$ i hipertenzivnom bolešću, cilj je zadržati SKP ispod $140 \mathrm{mmHg}(120-130 \mathrm{mmHg})$, kao i dijastolni ispod $80 \mathrm{mmHg}$ (Slika 1).

Randomizovane studije i meta-analize koje su analizirale kardiovaskularne ishode kod pacijenata sa $\mathrm{HBI} /$ proteinurijom koji su tretirani lekovima koji blokiraju renin-angiotenzin sistem, pokazale su redukciju i u KV mortalitetu i u progresiji $\mathrm{HBI}$, kao i u redukciji proteinurije kako kod dijabetične tako i kod nedijabetične nefropatije, sa napomenom da je efekat bio mnogo veći kod pacijenata sa proteinurijom. . $^{4,5}$ Prema postojećim dokazima preporučuje se terapija sa ACEI/ARB kod pacijenata bez dijabetesa i hipertenzije ukoliko je urinarna ekskrecija protein $\geq 1 \mathrm{~g} /$ dan, a ukoliko je prisutna hipertenzija onda je granica manja (0,5 g/dan). Važno je istaći da nema razlike u izboru ACEI kao i ARB, niti ARB imaju prednost u odnosu na ACEl ili da je opravdana kombinacija ACEI/ARB. S obzirom na ekonomske aspekte, preporučuje se prvo uvođenje ACEI, a tek onda kao zamena netolerantim pacijentima, prepisivanje terapije ARB.

Povišeni nivoi lipida su u epidemiološkim studijama istaknuti kao jedan od faktora koji predisponira nastanak $\mathrm{HBI}$, a na eksperimentalnim modelima je dokazano štetno dejstvo visokih nivoa triglicerida i LDL holesterola na mezangijalne ćelije dovodeći do njihove proliferacije kao i generalizovanog aterosklerotskog oštećenja koje ne zaobilazi ni renalne sudove..$^{6-8} \mathrm{~S}$ obzirom na to da HBI nije prepoznata kao poseban kardiovaskularni faktor rizika, preporuke za primarnu primenu statinske terapije kod pacijenata sa HBI se ne razlikuju u odnosu na opštu populaciju, dok je u sekundarnoj prevenciji kod pacijenata sa HBI i prethodnim KV događajem, njihova primena obavezna bez obzira na nivo lipida u krvi. Sama primena statina nema negativnih efekata na glomerulanu filtraciju i bubrežnu funkciju. Dislipidemija kod HBI ima svoje specifičnosti koje zavise pre svega od tipa bubrežnog oboljenja i stadijuma bolesti (dijabična nefropatija, dijaliza, terminalna $\mathrm{HBI}$ ), te su najčesće isprva povišene vrednosti triglicerida, dok LDL holesterol iako ne postiže visoke vrednosti, menja odnos svojih frakcija i postoje mnogo aterogeniji, dovodeći do ubrzane ateroskleroze.
U celini, kod bolesnika sa HBI i IBS potrebno je voditi računa o farmakokinetici i upotrebljavati lekove koji nemaju eliminaciju preko bubrega, odnosno prilagoditi dozu lekova koji imaju eliminaciju preko bubrega (npr. atenolol, sotalol, ACE inhibitori). Potrebno je na osnovu klirensa kreatinina podesiti dozu, ili ih zameniti lekovima koji se predominantno izlučuju preko jetre (propranolol, metoprolol, nebivolol, karvedilol, fosinopril, itd.). Rosuvastatin je kontraindikovan ako je klirens kreatinina $<30 \mathrm{ml} / \mathrm{min}$. Simvastatin i atorvstatin su klinički ispitani u $\mathrm{HBI}$, doza oba leka je maksimalno $10 \mathrm{mg} /$ dan ako je klirens kreatinina $<30 \mathrm{ml} / \mathrm{min}$.

\section{Izbor revaskularizacione strategije u zavisnosti od stadijuma HBI}

Kod bolesnika sa blagim $\left(60 \leq \mathrm{GFR} \leq 90 \mathrm{~mL} / \mathrm{min} / 1.73 \mathrm{~m}^{2}\right)$ do umerenim sniženjem GFR ( $30 \leq G F R \leq 60 \mathrm{~mL} / \mathrm{min} /$ $1.73 \mathrm{~m}^{2}$ ) postoji dosta konzistentnih dokaza da je hirurška revaskularizacija bolji terapijski izbor u odnosu na $\mathrm{PCl}$, pogotovo kod bolesnika kod kojih je dijabetes melitus uzročnik HBI, sa predlogom za „off-pump“ tipom hirurške intervencije. Kod bolesnika sa izraženom $\left(15 \leq \mathrm{GFR} \leq 30 \mathrm{~mL} / \mathrm{min} / 1.73 \mathrm{~m}^{2}\right)$ i terminalnom fazom bolesti (GFR $\leq 15 \mathrm{~mL} / \mathrm{min} / 1.73 \mathrm{~m}^{2}$ ) nema tako jasnih dokaza u korist hirurškog pristupa. Hirurgija kod ovih bolesnika donosi bolje dugoročne rezultate ali više intrahospitalnih događaja i komplikacija, dok suprotno važi za $\mathrm{PCl} u$ odnosu na CABG (Tabela 1). Sam izbor stentova za PCl, DES vs. BMS, nije jasno u korist DES-a, pošto u prilog DES-a govori samo ređa pojava rekurentne ishemije, dok na drugoj strani imamo dokazano veći rizik od rane i kasne tromboze sa odnosom rizika između 3,1 i 6,5.

Tabela 1. Specifične preporuke za bolesnike sa blagom do umerenom $\mathrm{HBI}$

\begin{tabular}{|l|c|c|c|}
\hline & $\begin{array}{c}\text { Klasa } \\
\text { preporuke }\end{array}$ & $\begin{array}{c}\text { Nivo } \\
\text { dokaza }\end{array}$ & $\begin{array}{c}\text { Refe- } \\
\text { rence }\end{array}$ \\
\hline $\begin{array}{l}\text { Hirurška revaskularizacija } \\
\text { ima prednost u odnosu } \\
\text { na PCl ukoliko težina } \\
\text { koronarne bolesti } \\
\text { opravdava indikaciju, rizik } \\
\text { od intervecije je primeren, } \\
\text { kao i očekivana dužina } \\
\text { života }\end{array}$ & Ila & B & 10,13 \\
\hline $\begin{array}{l}\text { „Off-pump“ hirurška } \\
\text { revaskularizacija ima } \\
\text { prednost u odnosu na } \\
\text { „on-pump“ }\end{array}$ & Ilb & B & 14 \\
\hline $\begin{array}{l}\text { Za PCl, DES imaju } \\
\text { prednost u odnosu na } \\
\text { BMS }\end{array}$ & Ilb & $\mathrm{C}$ & $/$ \\
\hline
\end{tabular}

\section{Kontrastom indukovana nefropatija}

Kontrastom indukovana nefropatija (CIN) predstavlja treći najčešći uzrok jatrogeno izazvanih akutnih bubrežnih insuficijencija u bolničkim uslovima, posle hirurgije i hipotenzije. Definiše se kao postproceduralno povećanje serumskog kreatinina ( $\mathrm{sCr}$ ) od $25 \%$ ili apsolutno gle- 
dano više od $0.5 \mathrm{mmol} / \mathrm{L}$, u odnosu na preproceduralnu vrednost, u prvih 5 dana od procedure. lako je oštećenje najčešće reverzibilno i GFR se vraća na prvobitnu vrednost u toku 2 nedelje, može doći i do trajnog oštećenja. S obzirom na to da nema apsolutno efikasnog postupka kojim se ova komplikacija može izbeći, preporučuje se pre svega prepoznavanje bolesnika sa povišenim rizikom od ove komplikacije (preegzistirajuća blaga bubrežna insuficijencija, dijabetes melitus, starost, niska EF, dehidratacija, upotreba nefotoksičnih lekova, hipotenzija, srčana insuficijencija itd), a zatim i primena preventivnih mera koje treba prilagoditi riziku i stanju bolesnika (Tabela 2). Najvažnija i najefikasnija mera je svakako limitacija količine kontrasta tako da odnos količine i GFR ne bude veći od 3,7 ili da maksimalna doza ne bude veća od $4 \mathrm{ml} / \mathrm{kg}$. ${ }^{11}$

Tabela 2. Preporuke za prevenciju CIN-a

\begin{tabular}{|c|c|c|c|c|}
\hline Intervencija & Doza & $\begin{array}{l}\text { Klasa } \\
\text { preporuke }\end{array}$ & $\begin{array}{c}\text { Nivo } \\
\text { dokaza }\end{array}$ & Ref \\
\hline \multicolumn{5}{|l|}{ Svi bolesnici sa HBI } \\
\hline $\begin{array}{l}\text { Optimalna medikamentna terapija } \\
\text { (beta blokatori, ARB ili ACE } \\
\text { inhibitori, statini) }\end{array}$ & Prema kliničkim indikacijama & I & A & 9 \\
\hline Hidratacija (fiziološki rastvor) & $\begin{array}{l}1 \mathrm{ml} / \mathrm{kg} / \mathrm{h} \text { (12 h pre i } 24 \mathrm{~h} \text { posle) } \\
0.5 \mathrm{ml} / \mathrm{kg} / \mathrm{h} \text { ukoliko } \mathrm{EF}<35 \% \text { ili NYHA }>2\end{array}$ & 1 & A & $15-18$ \\
\hline $\mathrm{N}$-acetilcistein & $\begin{array}{l}600-1200 \mathrm{mg} / \mathrm{d} \\
24 \mathrm{~h} \text { pre i } 24 \mathrm{~h} \text { posle }\end{array}$ & $\mathrm{IIb}$ & A & 16,17 \\
\hline Na-bikarbonatna $0.84 \%$ infuzija & $\begin{array}{l}1 \mathrm{~h} \text { pre procedure bolus }=\text { TT } \times 0.462 \mathrm{mEq} \\
+6 \mathrm{~h} \text { posle infuzija TT } \times 0.154 \mathrm{mEq}\end{array}$ & $\mathrm{IIb}$ & A & $\begin{array}{l}15,16 \\
17\end{array}$ \\
\hline \multicolumn{5}{|c|}{ Bolesnici sa blagom, umerenom ili izraženom HBI } \\
\hline $\begin{array}{l}\text { Upotreba nisko ili izo-osmolarnih } \\
\text { kontrasta (lopramide, lohexole, } \\
\text { lodixanol) }\end{array}$ & $<350 \mathrm{ml}$ total, ili $<4 \mathrm{ml} / \mathrm{kg}$ & 1 & A & $\begin{array}{l}19,20- \\
22\end{array}$ \\
\hline \multicolumn{5}{|l|}{ Bolesnici sa izraženom HBI } \\
\hline $\begin{array}{l}\text { Razmotriti profilaktičku } \\
\text { hemofiltraciju } 6 \text { h pre procedure }\end{array}$ & $\begin{array}{l}\text { Zamena tečnosti brzinom od } 1000 \mathrm{ml} / \mathrm{h} \\
\text { bez izmene težine bolesnika i infuzija } \\
\text { fiziološkog brastvora } 24 \mathrm{~h} \text { nakon }\end{array}$ & Ila & B & 23,24 \\
\hline $\begin{array}{l}\text { Elektivna hemodijaliza se ne } \\
\text { proporučuje kao preventivna mera }\end{array}$ & & III & B & 25 \\
\hline
\end{tabular}

\section{Konkomitantna terapija lekovima prilikom izlaga- nja kontrastnom sredstvu}

Uticaj konkomitantne terapije na bubrežnu funkciju je poznat, međutim jasnih dokaza o štetnosti ili koristi primene lekova tokom izlaganja kontrastnom mediju nema, i većina podataka i stavova dolazi iz manjih nerandomizovanih studija, kliničkih prezentacija slučajeva ili iz ekspertskog kliničkog iskustva. Međutim, s obzirom na njihovu potencijalnu štetnost/korist kao i učestalost primene potrebno je skrenuti pažnju na njihove efekte (Tabela 3).

\section{Literatura:}

1. Klahr S., Levey AS, Beck GJ, et al. The effects of dietary protein restriction and blood-pressure control on the progression of chronic renal disease. N Engl J Med 1994; 330 (13): 877-884.

2. Ruggenenti P., Perna A., Loriga G., et al. Blood-pressure control for renoprotection in patients with non-diabetic chronic renal disease (REIN-2): multicentre, randomised controlled trial. Lancet 2005; 365 (9463): 939-946.

3. Wright JT, Jr., Bakris G, Greene T., et al. Effect of blood pressure lowering and antihypertensive drug class on progression of hypertensive kidney disease: results from the AASK trial. JAMA 2002; 288 (19): 2421-2431.

4. Kunz R., Friedrich C., Wolbers M., et al. Meta-analysis: effect of monotherapy and combination therapy with inhibitors of the renin angiotensin system on proteinuria in renal disease. Annf Intern Med 2008; 148 (1): 30-48.

5. Anon. Randomised placebo-controlled trial of effect of ramipril on decline in glomerular filtration rate and risk of terminal renal failure in proteinuric, non-diabetic nephropathy. The GISEN Group (Gruppo Italiano di Studi Epidemiologici in Nefrologia). Lancet 1997; 349 (9069): 1857-1863.

6. Oda H., Keane WF. Recent advances in statins and the kidney Kidney International - Supplement. 1999; 71: S2-5, 1999 Jul.: S2-S5.

7. Oda H., Keane WF. Lipids in progression of renal disease. Kidney International - Supplement. 1997; 62: S36-8, 1997 Nov.: S36S38.

8. O'Donnell MP, Kasiske BL, Kim Y., et al. Lovastatin inhibits proliferation of rat mesangial cells. J Clin Invest 1993; 91: 83-87.

9. Poldermans D., Bax JJ, Boersma E., et al. Guidelines for preoperative cardiac risk assessment and perioperative cardiac management in non-cardiac surgery: the Task Force for Preoperative Cardiac Risk Assessment and Perioperative Cardiac Management in Non-cardiac Surgery of the European Society of Cardiology (ESC) and endorsed by the European Society of Anaesthesiology (ESA). Eur Heart J., 2009; 30: 2769-2812.

10. Brener SJ, Lytle BW, Casserly IP, Schneider JP, Topol EJ, Lauer MS. Propensity analysis of long-term survival after surgical or percutaneous revascularization in patients with multivessel coronary artery disease and high-risk features. Circulation 2004; 109: 2290-2295.

11. Herzog CA, Ma JZ, Collins AJ. Comparative survival of dialysis patients in the United States after coronary angioplasty, coro- 
Tabela 3. Lekovi koji se koriste u kardiologiji i bubrežna funkcija

\begin{tabular}{|c|c|c|c|c|}
\hline Grupa & Efekat & Klasa dokaza & Lekovi & Preporuka \\
\hline \multicolumn{5}{|c|}{ Lekovi koji mogu uticati na renalnu hemodinamiku pre i tokom izlaganja kontrastu } \\
\hline $\begin{array}{l}\text { Nesteroidni } \\
\text { antiimflamatorni lekovi } \\
\text { (NSAID) i inhibitori } \\
\text { ciklooksigenaze } 2 \\
\text { (COX-2) }\end{array}$ & $\begin{array}{l}\text { Renalna vazokonstrikcija (smanjenje } \\
\text { prostaglandina, povećanje efekta } \\
\text { adenozina) }\end{array}$ & $\mathrm{B}, \mathrm{C}$ & $\begin{array}{l}\text { Aspirin, } \\
\text { Indo- } \\
\text { metacin, } \\
\text { Brufen }\end{array}$ & $\begin{array}{l}\text { Isključenje pre izlaganja kontrastu, } \\
\text { zamena za druge analgetike }\end{array}$ \\
\hline Antihipertenzivni lekovi & $\begin{array}{l}\text { Uzrokovanje hipotenzije i smanjenje } \\
\text { renalne perfuzije (povećanje } \\
\text { toksičnosti kontrastnog medija ) }\end{array}$ & B & \begin{tabular}{|l|} 
ARB, ACE \\
inhibitori \\
(Kaptopril) \\
\end{tabular} & $\begin{array}{l}\text { Monitoring pritiska, održavanje } \\
\text { sistemske arterijske tenzije }\end{array}$ \\
\hline Dopamin & $\begin{array}{l}\text { Moguće povećanje renalne perfuzije } \\
\text { u tkz. „renalnoj dozi”, pozitivan } \\
\text { inotropni efekat }\end{array}$ & A & & $\begin{array}{l}\text { Nema dokaza o efektu, ali } \\
\text { pozitivan inotropni efekat može u } \\
\text { određenim situacijama popraviti } \\
\text { renalnu perfuziju }\end{array}$ \\
\hline Diuretici & $\begin{array}{l}\text { Hipotenzija, hiperkalemija za } \\
\text { K-štedeće diuretike }\end{array}$ & B & $\begin{array}{l}\text { Spirono- } \\
\text { lakton, } \\
\text { tiazidni } \\
\text { diuretici, } \\
\text { furosemid } \\
\end{array}$ & $\begin{array}{l}\text { Primena uporedo sa hidratacijom } \\
\text { pacijenta (sprečavanje } \\
\text { preopterećenja tečnostima) }\end{array}$ \\
\hline \multicolumn{5}{|c|}{ Lekovi koji mogu uzrokovati direktnu tubularnu toksičnost } \\
\hline Manitol & $\begin{array}{l}\text { Osmotska diureza, direktna } \\
\text { toksičnost na tubule }\end{array}$ & B & & $\begin{array}{l}\text { Najčešća primena kod neuroloških } \\
\text { pacijenata, uzdržati se od primene } \\
\text { periproceduralno }\end{array}$ \\
\hline $\begin{array}{l}\text { Aminoglikozidni } \\
\text { antiobitici }\end{array}$ & $\begin{array}{l}\text { Direktna medularna i instersticijalna } \\
\text { oštećenja }\end{array}$ & A & & $\begin{array}{l}\text { Jednokratna primena leka, } \\
\text { uzdržavanje od primene } 6-8 \mathrm{~h} \text { kod } \\
\text { osoba sa normalnom bubrežnom } \\
\text { funkcijom, } 24 \text { h kod osoba sa } \\
\text { smanjenom bubrežnom funkcijom }\end{array}$ \\
\hline \multicolumn{5}{|c|}{ Lekovi koji mogu delovati postproceduralno nakon izlaganja kontrastu } \\
\hline Metformin & $\begin{array}{l}\text { Moguca laktična acidoza kod } \\
\text { pacijenata sa smanjenom bubrežnom } \\
\text { funkcijom i DM tip II }\end{array}$ & B & Gluformin & $\begin{array}{l}\text { Isključenje na dan primene i } \\
\text { narednih } 24-48 \mathrm{~h} \text { nakon procedure } \\
\text { kod pacijenata sa DM tip II (i/ili } \\
\text { smanjenom bubrežnom funkcijom) }\end{array}$ \\
\hline Statini & Moguć protektivni efekat & B & & $\begin{array}{l}\text { Uobičajena primena } \\
\text { periproceduralno }\end{array}$ \\
\hline
\end{tabular}

nary artery stenting, and coronary artery bypass surgery and impact of diabetes. Circulation 2002;106:2207-2211.

12. Szczech LA, Reddan DN, Owen WF, et al. Differential survivl after coronary revascularization procedures among patients with renal insufficiency. Kidney Int 2001; 60: 292-299.

13. Sajja LR, Mannam G., Chakravarthi RM, et al. Coronary artery bypass grafting with or without cardiopulmonary bypass in patients with preoperative non-dialysis dependent renal insufficiency: a randomized study. J Thorac Cardiovasc Surg 2007; 133: 378-388.

14. Laskey WK, Jenkins C., Selzer F., et al. Volume-to-creatinine clearance ratio: a pharmacokinetically based risk factor for prediction of early creatinine increase after percutaneous coronary intervention. J Am Coll Cardiol 2007; 50: 584-590.

15. Brar SS, Shen AY, Jorgensen MB, et al. Sodium bicarbonate vs sodium chloride for the prevention of contrast medium-induced nephropathy in patients undergoing coronary angiography: a randomized trial. JAMA 2008;300:1038-1046.

16. Briguori C., Airoldi F., D’Andrea D., et al. Renal Insufficiency Following Contrast Media Administration Trial (REMEDIAL): a randomized comparison of 3 preventive strategies. Circulation

17. Marenzi G., Assanelli E., Marana I., et al. N-acetylcysteine and contrast-induced nephropathy in primary angioplasty. N Engl J Med 2006; 354: 2773-2782.

18. Merten GJ, Burgess WP, Gray LV, et al. Prevention of contrastinduced nephropathy with sodium bicarbonate: a randomized controlled trial. JAMA 2004; 291: 2328-2334.
19. Laskey WK, Jenkins C., Selzer F., et al. Volume-to-creatinine clearance ratio: a pharmacokinetically based risk factor for prediction of early creatinine increase after percutaneous coronary intervention. J Am Coll Cardiol 2007; 50: 584-590.

20. Aspelin P., Aubry P., Fransson SG, Strasser R., Willenbrock R., Berg KJ. Nephrotoxic effects in high-risk patients undergoing angiography. N Engl J Med 2003; 348: 491-499.

21. Jo SH, Youn TJ, Koo BK, et al. Renal toxicity evaluation and comparison between visipaque (iodixanol) and hexabrix (ioxaglate) in patients with renal insufficiency undergoing coronary angiography: the RECOVER study: a randomized controlled trial. J Am Coll Cardiol 2006; 48: 924-930.

22. Solomon RJ, Natarajan MK, Doucet S., et al. Cardiac Angiography in Renally Impaired Patients (CARE) study: a randomized doubleblind trial of contrast-induced nephropathy in patients with chronic kidney disease. Circulation 2007;115: 3189-3196.

23. Marenzi G, Marana I, Lauri G, et alL. The prevention of radiocontrast-agent-induced nephropathy by hemofiltration. N Engl J Med 2003; 349: 1333-1340.

24. Marenzi G., Lauri G., Campodonico J., et al. Comparison of two hemofiltration protocols for prevention of contrast-induced nephropathy in high-risk patients. Am J Med 2006; 119: 155-162.

25. Vogt B., Ferrari P., Schönholzer C., et al. Prophylactic hemodialysis after radiocontrast media in patients with renal insufficiency is potentially harmful. Am J Med 2001; 111: 692-698. 